\title{
A ATUAÇÃO DO ASSISTENTE SOCIAL NAS INSTÂNCIAS DE CONTROLE DEMOCRÁTICO NO BRASIL: POLÍTICA DE SEGURIDADE SOCIAL
}

\author{
The performance of social worker in the instances of democratic control in Brazil: \\ social security policy
}

OLIVEIRA, Carina ${ }^{1}$, MORGADO, Elsa ${ }^{2}$, RODRIGUES, João ${ }^{3}, \&$ LEONIDO, Levi ${ }^{4}$

\begin{abstract}
Resumo
O presente artigo tem como objetivo abordar a evolução da política de seguridade social, aspectos relacionados à cidadania, bem como o trabalho do assistente social nos espaços de controlo democrático, especificamente os conselhos no âmbito das três esferas de gestão pública do Brasil: municipal, estadual e federal. O procedimento metodológico utilizado foi à pesquisa bibliográfica destacando aquelas ligadas ao tema sobre políticas públicas, cidadania e atuação do assistente social nos conselhos. Nesses espaços, a atuação dos assistentes sociais se torna de suma importância para enfatizar sua dimensão educativa e a busca na consolidação de direitos das instâncias políticas, bem como da participação destes nos espaços públicos de legitimação da cidadania.
\end{abstract}

\begin{abstract}
This article aims to deal with the evolution of social security policy, aspects related to citizenship, as well as the work of the social worker in the areas of democratic control, specifically the councils within the three spheres of public management in Brazil: municipal, state and Federal. The methodological procedure used was the bibliographical research highlighting those related to the topic on public policies, citizenship and social worker on councils. In these spaces, the work of social workers becomes crucial to emphasize their educational dimension and the search for the consolidation of the rights of the political organs, as well as their participation in the public spaces of legitimation of citizenship.
\end{abstract}

Palabras-clave: Seguridade Social; Assistente Social; Politicas Públicas; Cidadania; Democracia.

Key-words: Social Security; Social Worker; Public policy; Citizenship; Democracy.

Data de submissão: setembro de 2018 | Data de aceitação: dezembro de 2018.

\footnotetext{
${ }^{1}$ CARINA SILVA DE CARVALHO OLIVEIRA - Universidade Estadual de Feira de Santana, BRASIL.

E-mail: carinauefs@gmail.com.

${ }^{2}$ ELSA MARIA GABRIEL MORGADO - Centro de Estudos Filosóficos e Humanísticos, PORTUGAL. E-mail: elsagmorgado@Gmail.Com

${ }^{3}$ JOÃO BARTOLOMEU RODRIGUES - Universidade de Trás-os-Montes e Alto Douro, PORTUGAL. E-mail: jbarto@utad.pt,

${ }^{4}$ LEVI LEONIDO FERNANDES DA SILVA - Universidade de Trás-os-Montes e Alto Douro | CITAR UCP, PORTUGAL. E-mail: levileon@utad.pt,
} 


\section{INTRODUÇÃO}

Este artigo versa sobre a construção histórica da seguridade social no Brasil retratando as mudanças efetivas para as garantias dos direitos sociais, bem como a consolidação deste sistema de proteção, destacando também a importância do trabalho do assistente social nas instâncias de controle democrático para o fortalecimento das políticas públicas. A seguridade social é definida na Constituição Federal de 1988, no artigo 194, caput, como um "conjunto integrado de ações de iniciativa dos poderes públicos e da sociedade, destinadas a assegurar os direitos relativos à saúde, à previdência e à assistência social". A Constituição consolidou os direitos civis, políticos, sociais e os chamados direitos difusos. Foi um marco no que se refere aos direitos sociais. Ao mesmo tempo, trouxe enormes desafios no que tange a efetivação dessas políticas. A Carta Magna definiu os direitos sociais como direitos universais e inalienáveis do cidadão, rompendo com a lógica da cidadania regulada.

O’Donnell (2011) define a cidadania política e afirma que está atrelada a garantia do direito de todos os indivíduos, elencando também a liberdade de votar, participar de associações, movimentos sociais e participar de eleições limpas por meio da competição entre partidos políticos, tentando também ser eleitos, se assim desejarem. Ainda segundo a concepção de O’Donnell a condição da cidadania é complexa e vai além, necessita de empoderamento dos indivíduos para que utilizando-se da liberdade orientem suas escolhas da garantia plena dos direitos, liberdades e obrigações de todos, independente de sua posição social.

A Constituição Federal, ao atribuir ao Brasil à forma de Estado Democrático de Direito, determina que as decisões estatais estejam alicerçadas na vontade popular e subordinadas aos direitos e garantias fundamentais, em especial àqueles que dizem respeito à liberdade, igualdade e justiça. A Administração Pública com base nesses conceitos preconiza que todos os indivíduos exerçam amplamente o poder político. Tal afirmação tem base nos normativos da Organização dos Estados Americanos-OEA, que reconhece a participação social como um dos instrumentos para o alcance da democracia, onde o Estado passa a ter o encargo de administrar a aplicação dos princípios constitucionais de uma democracia participativa e a sua aplicação jurídica com os princípios da soberania popular. 
O trabalho desenvolvido pelo assistente social na assessoria aos conselhos possibilita maior estruturação e ampliação desses espaços democráticos, estimulando a atuação dos indivíduos no planejamento das ações e na fiscalização dos serviços prestados no âmbito das garantias previstas na Constituição de 1988. Pode atuar também como conselheiro, tendo a sua representação ligada a sociedade civil, ou governamental. O trabalho deste profissional torna-se relevante como instrumento para o empoderamento da população demantaria dos serviços no que tange a conquista do direito de participar e decidir, principalmente por parte do segmento dos usuários e trabalhadores de saúde, da assistência social, educação, criança e adolescente, idosos, mulheres, deficientes, entre outros, direcionando-os para a prática do controle social e das efetivas ações destes conselhos para o exercício da democracia.

\section{A CIDADANIA: no Brasil}

Segundo Botelho e Moritz (2001) o conceito de cidadania ganhou relevância na polis grega e mais do que isso foi identificado com o surgimento da burguesia na idade média. Contudo, é na passagem para modernidade que ela adquire fundamentos filosóficos na tradição contratualista de John Locke e Jean Jaques Rousseau. Ganhando importância, através destes filósofos, a ideia de um contrato firmado entre os cidadãos e Estado. Sendo essa concepção desafiada na modernidade pela noção de "direitos dos homen", cuja primeira expressão é o conceito de jusnaturalismo. Ou seja, o estado natural aparece como a condição da liberdade individual dos homens, que precede a formação da comunidade política.

O'Donnell (2011) define a cidadania política e afirma que está atrelada a garantia do direito de todos os indivíduos, elencando também a liberdade de votar, participar de associações, movimentos sociais e participar de eleições limpas por meio da competição entre partidos políticos, tentando também ser eleitos, se assim desejarem.

Afirma ainda que a condição da cidadania é complexa, sendo ela adscritiva que se explica pelo fato do individuo nascer naquele território ou sua descendência; é potencialmente empoderadora, pois os indivíduos podem utilizam-se da liberdade para orientar suas escolhas; é limitadamente universalista, pois atribui a todos os adultos, dentro da jurisdição do estado, direitos iguais, desde que satisfaçam os critérios de nacionalidade; é condição formal, pois existem normas legais para garanti-la; e por fim é 
pública devendo cumprir rigorosamente critérios de publicização, bem como ser um sistema de garantia plena dos direitos, liberdades e obrigações de todos, independente de sua posição social.

A cidadania no Brasil foi marcada por avanços e retrocessos no que tange a garantia de direitos. Segundo a definição clássica de Marshall, a cidadania está dividida em três gerações de direitos: direitos civis, no século XVIII; os direitos políticos, no século XIX, e; os direitos sociais, no século XX. Se fizermos uma analise sobre o Brasil, percebemos através dos momentos históricos de conquistas dos direitos sociais, sem garantia dos direitos civis, a exemplo do período do regime militar.

No Brasil o presidente Getúlio Vargas despendeu atenção à questão trabalhista e social. Várias leis foram elaboradas e promulgadas, resultando posteriormente na Consolidação das Leis do Trabalho (CLT) em 1943. A CLT, introduzida no Estado Novo, teve longa duração, permaneceu e passou pelo processo de democratização de 1945 e está em vigor até os dias atuais. A era Vargas, período entre 1930 a 1945 foi o momento da legislação social, pautado e implementado com baixa participação política e precária vigência dos direitos civis e políticos. Segundo José Murilo de Carvalho (200, p.110) "Este pecado de origem e a maneira como foram distribuídos os benefícios sociais tornaram duvidosa sua definição como conquista democrática e comprometeram em parte sua contribuição para o desenvolvimento de uma cidadania ativa".

Ainda Segundo André Botelho e Lilia Moritz (2001) o percurso da cidadania no Brasil seguiu alguns rumos e destacam-se entre eles: o fato do país tornar-se independente com a maior parte da população excluída dos direitos civis e políticos sem sequer estar mobilizada por um sentido de nacionalidade; uma monarquia, cercada de república que impusera submissão, colocando em questão o status do individuo como cidadão atrelado ao longo período da escravidão e seu legado provoca limites cruciais à cidadania; os homens livres, em condições de pauperismo estavam sujeitos às estruturas de dominação tradicional como o mandonismo, coronelismo e relações de favor; uma concepção de direitos garantidos pela esfera pessoal e privada do que à esfera oficial e pública; a fase da Primeira República fora marcada por fortes contradições; com o Estado Novo o Brasil reconhece a cidadania com a concepção de direitos sociais (legislação trabalhista) em detrimento dos direitos civis e políticos; com Juscelino Kubitschek apesar do desenvolvimentismo não altera-se os gaps sociais; o Golpe de 1964 cessam os direitos civis e políticos; a transição democrática do final dos anos 70 e a constituição de 1988; modelo exemplar no que tange ao sistema eleitoral, sexta potência mundial, segundo 
dados de 2012, contudo ainda permanece com taxas elevadas de analfabetismo, desemprego e mortalidade; corrupção interna, uso da máquina pública para fins ilícitos, violência policial, segundo os autores supra mencionados, são desafios para a cidadania nacional.

Constata-se que no campo da seguridade social, tal como foi estabelecido na Constituição vigente, a lógica do seguro social apoiou-se no critério do trabalho e não no da cidadania, com exceção dos serviços de saúde e assistência social, a previdência social fortalece a ideia do direito como corporativa, privilegiando os trabalhadores formais, reafirmando a lógica daquele que pode pagar, ou aqueles que possuem vínculos empregatícios, ou seja, o amparo ao trabalhador que tem registro formal excluindo, desta forma, grande parte dos trabalhadores, que por estarem em situação de informalidade (tanto urbanos e, sobretudo rurais), não tem as garantias de acesso a esses direitos sociais.

\subsection{A CONSTRUÇÃO HISTÓRICA: da Seguridade Social no Brasil}

A política de assistência no país historicamente foi sendo construída a partir do assistencialismo pautados na benemerência, na caridade e filantropia. Essas são características fundantes que são contrários à ideia de garantia dos direitos dos usuários com vistas ao empoderamento do sujeito. Assistência Social é política pública de atenção, de defesa de direitos, de cidadania e de dignidade humana, enquanto que o assistencialismo é o contraponto do direito, da proteção social ou seguridade social.

O assistencialismo não garante cidadania, o acesso aos direitos se dá como um favor, tutela, pela compra do voto, por exemplo. Todavia essa realidade ainda permanece muito presente no Brasil apesar da gama de leis que garantem ao usuário acesso aos bens e serviços disponíveis, ou de políticas públicas, para quem dela necessitar, sendo dever do Estado criar condições de permanência e acesso aos usuários do serviço, bem como oferecer qualidade no atendimento prestado.

A discussão sobre assistência social e assistencialismo se processa na atualidade sob a perspectiva da Assistência Social como Política de Seguridade Social que deve ser pensada enquanto possibilidade de ressignificação desse "indivíduo assistido"- usuário dos serviços de assistência social - que vive a ausência ou a insuficiência de renda, pertencente a segmentos vulnerabilizados. 
Data-se que até a década de 40 ainda se evidenciava as ideias de caridade e filantropia. Prova disso é a criação da Legião Brasileira de Assistência (LBA), extinta em 1995 após diversos escândalos envolvendo os gestores da época, ocorridos por desvios de verbas. A referida instituição foi criada com o objetivo de dar apoio às famílias dos soldados enviados para o combate na segunda guerra mundial. O marco e o avanço para a construção do direito do usuário só começa a ser pensada no país a partir da Constituição de 1988, a lei se configura uma ruptura histórica para a garantia do direito.

As políticas sociais sofreram grande impacto a partir da década de 80, com o surgimento da política neoliberal, trazendo reflexos diretos na condução dessas garantias conquistadas na Constituição de 1988. O Estado de Bem-Estar Social, nunca antes vividos no país, teve um ataque direto, haja vista a retração do Estado no que tange a garantia dos direitos sociais com vistas ao atendimento primordial para a necessidade do capital.

O Estado passa a não regular mais a economia com o discurso de que este não tem mais condições de arcar com as despesas da seguridade social, aumentando assim, a informalidade no trabalho, a precariedade nos serviços públicos e a dificuldade de acesso à universidade pública de qualidade. É neste contexto que começam a surgir segmentos sociais que passam a cobrar atenção para suas necessidades básicas, descritas como essenciais para o individuo, exigindo a intervenção de políticas sociais especificas. Segundo Mota (2008, p.28):

A consolidação de direitos sociais e trabalhistas e a oferta de serviços
sociais públicos, ao mesmo tempo em que foram responsáveis pelo
reconhecimento da necessidade de proteção social dos trabalhadores,
também possibilitaram o surgimento de ideologias que defendiam a
possibilidade de compatibilizar, bem-estar e democracia, lastro político
da social democracia - lastro que perdurou durante as "três décadas
gloriosas". E enquanto países centrais viviam o "pleno emprego" e a
expansão da seguridade, garantindo a reprodução da virtuosidade do
crescimento econômico com desenvolvimento social, na periferia
mundial assistia-se à defesa da modernização e do desenvolvimentismo
como meio de integração menos onerosa desses países à ordem
econômica mundial.

A política social desta forma surge para permitir aos cidadãos acessar os recursos e as garantias de bens e serviços necessários com vistas ao exercício pleno dos seus direitos no que tange ao atendimento dos múltiplos aspectos, entre eles, social, econômico, cultural, político. Ela também permite a cobertura dos riscos sociais, a garantia dos mínimos previstos na Carta Magna, a condições de moradia, saúde, educação, ao trabalho, ao lazer e o combate às desigualdades no país. 
Aliado a esse discurso, as políticas sociais passam a atender apenas aqueles que estão na chamada extrema pobreza, esta entendida como algo que faz parte dos reflexos da questão social. "Questão Social que se reformula e se redefine, mas permanece substantivamente a mesma por se tratar de uma questão estrutural que não se resolve numa formação econômico social por natureza excludente" (Yazbek,1995, p. 33). Em 1993, surge a Lei Orgânica da Assistência Social, mais conhecida como LOAS. Essa lei inaugura uma nova direção para a política de assistência social no Brasil. Ela traz em seu bojo a garantia da política pautada através de princípios e diretrizes, propondo uma mudança estrutural e conceitual na assistência social pública, criando assim novas estratégias e práticas que impulsionam as relações entre organizações governamentais e sociedade.

A Secretaria de Estado de Assistência Social é criada em 1999, a partir daí surge a Política Nacional de Assistência Social - PNAS, visando criar um sistema descentralizado e participativo, posteriormente foi criada a Norma Operacional Básica NOB que estabelecia níveis de gestão para que os municípios de todo país pudessem ter acesso aos recursos disponíveis com a finalidade de associar gestão e financiamento, definindo assim os requisitos de responsabilidade e incentivos para cada nível de gestão. Quanto às implicações da centralidade da assistência social na seguridade social brasileira a partir de 1990 e 2000, Mota (2008, pp. 133-134) afirma que:

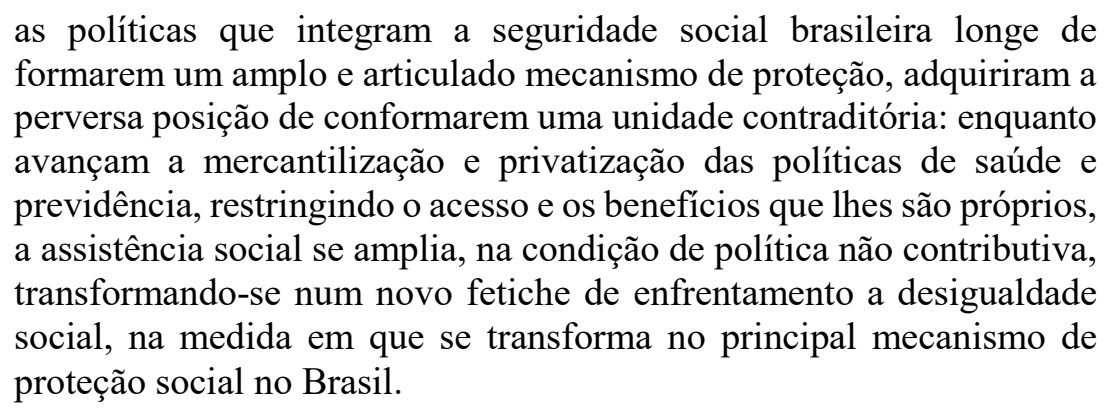

Só em 2005, surge o Sistema Único de Assistência Social que tem como objetivo reordenar a política de assistência social na perspectiva de propiciar a efetivação das ações, aumentando a sua cobertura, visando o atendimento integral ao individuo. Neste sentido, a política de assistência está organizada por tipo de proteção, são elas: a básica e especial, conforme a natureza da proteção social e por níveis de complexidade no atendimento, conforme descrito na PNAS. 
Entretanto, vale ressaltar que essa política só foi implementada através das manifestações dos indivíduos e famílias em função do acirramento das mazelas da questão social, fruto dos reflexos oriundos do sistema capitalista. Behring (2009, p. 304), afirma que:

A lógica liberal funda-se na procura do interesse próprio pelos indivíduos, portanto, seu desejo supostamente natural de melhorar as condições de existência, tende a maximizar o bem-estar coletivo. Os indivíduos, nesta perspectiva, são conduzidos por uma mão invisível o mercado - a promover um fim que não fazia parte de sua intenção inicial.

Portanto, nenhuma política social surge por acaso, ela é resultado das lutas da sociedade, dos movimentos sociais e tem por finalidade minimizar os reflexos causados pela desigualdade social, pobreza, fome, violência, desemprego, falta de acesso à saúde, falta de acesso à educação de qualidade. A classe dominante precisa manter os mínimos sociais para não perder o poder como detentor do capital os ganhos obtidos através da mais valia, servem para retroalimentar o próprio sistema capitalista. De acordo com dados do IPEA (2012, Brasil, 2012d):

Como resultado, entre as políticas que compõem o Sistema de Seguridade Social brasileiro, a assistência social foi a que apresentou a maior taxa de crescimento no financiamento de 2002 a 2012. De R\$ 6,5 bilhões, em 2002, os recursos destinados à área atingiram $\mathrm{R} \$ 56,5$ bilhões, em 2012. No período de 2004 a 2011, o financiamento federal da assistência social saltou de $0,71 \%$ do produto interno bruto (PIB) para $1,10 \%$ (Brasil, 2012d). Além do PBF e da crescente ampliação do acesso ao Benefício de Prestação Continuada (BPC), estes resultados se devem também à implantação do Suas no país, a partir de 2005, e aos investimentos em serviços, programas, projetos socioasssistenciais e no aprimoramento da gestão, particularmente incrementados a partir de 2010, em razão das agendas prioritárias nacionais que passam a incorporar o sistema e suas ofertas.

O Sistema Único de Assistência Social traz um grande desafio no que tange a formulação e implantação de inovadores e transformadoras metodologias de trabalho socioassistencial, contribuindo para o exercício da cidadania e emancipação do sujeito. Neste sistema, os serviços, programas, projetos e benefícios da assistência social são reorganizados através de níveis de proteção, bem como possui princípios, diretrizes e objetivos.

Bobbio (1992, p. 16) aduz que: “o problema fundamental em relação aos direitos do homem, hoje, não é tanto o de justificá-los, mas o de protegê-los. Trata-se [portanto] de um problema não filosófico, mas político". A luta dos movimentos sociais é importante para a construção de uma sociedade mais justa. Sabe-se que ao longo do período histórico 
do Brasil, o país viveu diversos modelos de governo. As políticas de bem estar social nunca chegaram a existir de forma efetiva, entretanto alguns teóricos afirmam que ela começou a ser implantada a partir da Constituição de 1988, contudo logo sofreu os impactos das grandes reformas, baseados nos modelos de gestão neoliberal, com isso, o Estado passou a reduzir os gastos com a seguridade social que compreende a saúde, a assistência social e a previdência.

\subsection{O Assistente Social nos espaços de controle democrático}

De acordo com a Lei 8662/93 que dispõe sobre a profissão do assistente social em seu Artigo $4^{\text {o }}$, afirma que compete ao profissional: "I- elaborar, implementar, executar e avaliar políticas sociais junto a órgãos da administração pública, direta ou indireta, empresas, entidades e organizações populares". Reafirmando o vínculo da categoria com as políticas publicas. Por conseguinte seu inciso II, deste mesmo artigo supra citado, ratifica o inciso anterior, e aduz que "elaborar, coordenar, executar e avaliar planos, programas e projetos que sejam do âmbito de atuação do Serviço Social com participação da sociedade civil", evidenciando essa atuação na pratica do profissional, vinculado ao projeto ético-politico. De acordo com Iamamoto (2010, p. 198):

A atuação dos assistentes sociais junto aos conselhos gestores tem se ampliado, com destaque para os conselhos de saúde e de assistência social. Esse fenômeno deve-se, em grande medida, à "inserção privilegiada" do Serviço Social no âmbito das políticas sociais, desenvolvendo, principalmente, um trabalho de alta relevância nas políticas da Seguridade Social, em sua execução, planejamento, gestão, monitoramento e avaliação. A "inserção privilegiada" do assistente social junto às políticas de proteção social refere-se à particularidade interventiva do profissional em lidar cotidianamente com as "múltiplas e diversificadas expressões da questão social.

O assistente social ao longo da sua historia profissional teve papel fundamental como executor de políticas públicas. Com a ampliação dos espaços democráticos a partir da criação e implementação dos conselhos nas diversas esferas publicas, o assistente social passou a atuar diretamente como conselheiros e consequentemente ampliando os espaços de atuação desta categoria. Assim, a análise da participação do assistente social nos conselhos deve considerar os pilares éticos, teórico-metodológicos e sócio-históricos que fundamentam a direção sociopolítica da profissão. 
A base desse conteúdo ideológico e político é o projeto ético-político profissional hegemônico na profissão a partir da década de 1980, representando um marco do movimento de ruptura do Serviço Social com o tradicional conservadorismo na profissão (Paulo Netto, 1999). Com base nessas considerações acima, Raichelis (2000, p. 11) afirma que:

\begin{abstract}
Neste contexto, ganha destaque a participação dos assistentes sociais que, como é sabido, tem sido uma das categorias com maior presença nos Conselhos em suas diferentes áreas. A contribuição dos assistentes sociais para fazer avançar a esfera pública no campo das políticas sociais é irrecusável. Mas, impõe-se à profissão e aos profissionais a colaboração cada vez mais qualificada, tanto do ponto de vista teóricometodológico como sobretudo ético-político, para atuar nos Conselhos e Fóruns, em seus vários níveis, notadamente no plano municipal, onde a força das elites locais se faz mais presente.
\end{abstract}

A atuação profissional nos conselhos gestores deve contribuir para a modificação das relações sociais e políticas resgatando a soberania popular. Todavia, para efetivação desta premissa, torna-se necessária a presença de alguns elementos na esfera pública. Ainda segundo Raichelis (2000, p.13) são eles:

a) a visibilidade das ações e dos discursos dos sujeitos expressos com transparência; b) o controle social que envolve o acesso aos processos de informação das decisões da sociedade; c) a representação de interesses coletivos que implica a constituição de sujeitos sociais ativos, presentes na cena pública a partir da qualificação de demandas coletivas; d) a democratização que remete à ampliação dos fóruns de decisão política extrapolando os condutos tradicionais de representação e permite incorporar novos sujeitos sociais como protagonistas e contribuir para criar e consolidar novos direitos; e e) a cultura pública que supõe o enfrentamento do autoritarismo social e da "cultura privatista" e a apropriação do público pelo privado.

Contudo diante da precarização dos serviços públicos, agravados pelos cortes de gastos para atender as políticas de seguridade social, principalmente no que tange a saúde e assistência social, a má administração dos recursos e da falta de gestores comprometidos com os interesses coletivos, torna-se de suma importância que o profissional esteja atento às contradições inerentes aos espaços dos conselhos, haja vista que os interesses antagônicos permeiam esses espaços, tornando-os desafiadores para a garantia dos direitos sociais, num cenário de regressão das conquistas históricas da classe trabalhadora. 


\section{CONSIDERAÇÕES FINAIS}

O novo sistema de proteção da seguridade social passou a ser organizado a partir de um modelo que cria condições necessárias a democratização do amparo social, ampliação dos direitos da população, bem como o rompimento que restringia o uso exclusivo do cidadão contribuinte aos serviços de políticas sociais, ou seja, ampliaram-se os serviços não contributivos e configurou-se a possibilidade de universalização do acesso. Entretanto no que se refere à previdência social do país, se faz necessário avanços para garantia efetiva dos direitos dos demandatarios que não possuem vinculo formal. Sobre cidadania é possível perceber não basta apenas criar os espaços de luta coletiva se faz necessário ampliar a discursão sobre políticas públicas efetivas, de garantia plena dos direitos, para uma prática cotidiana comum a todos os cidadãos em especial aqueles que estão historicamente espoliadas no Brasil e consequentemente tornar o País equânime e igualitário. No que tange a atuação do assistente social nas instancias de controle democrático do país, a partir da constituição de 1988, da criação das leis que regulamentaram os conselhos em cada esfera governamental, propiciou o aumento do espaço ocupacional da categoria, haja vista que além de atuar como executor das políticas públicas, o assistente social passou a ter representação significativa nos conselhos como gestor, conselheiro, interlocutor e representante dos interesses da maioria da população. Outro aspecto relevante para o profissional é que com os espaços dos conselhos a categoria pode reassumir o trabalho de base, de mobilização, de organização popular, de organização política mesmo diante do refluxo de alguns movimentos sociais, o que torna um grande desafio diante dos ditames impostos pelo Estado para atender os interesses do capital.

\section{REFERÊNCIAS BIBLIOGRÁFICAS}

Behring, E. R., \& Boschetti, I. (2007). Politica social: fundamentos e história. (3. ed.). São Paulo: Cortez.

Botelho, A., \& Schwarcz, L. M. (2012). Introdução - Cidadania e direitos: aproximações e relações. In A. Botelho \& L. M. Schwarcz (Org.), CIDADANIA, UM PROJETO EM CONSTRUÇÃO - Minorias, justiça e direitos. São Paulo: Claro Enigma.

Bobbio, N. (1992). A era dos direitos. Rio de Janeiro: Campus. 
Carvalho, J. M. (2003). Cidadania no Brasil: o longo caminho. (4ª ed.). Rio de Janeiro: Civilização Brasileira.

Iamamoto, M. V. (1998). O Serviço Social na contemporaneidade: trabalho e formação profissional. São Paulo: Cortez.

Iamamoto, M. V. (2009). Os espaços sócio-ocupacionais do assistente social. In CFESSABEPSS (Org.), Serviço Social: direitos sociais e competências profissionais. $O$ significado do trabalho do assistente social nos distintos espaços sócio-ocupacionais (pp. 341-376). Brasília: Cfess/Abepss.

Iamamoto, M. V. (2010). Serviço Social em tempo de capital fetiche: capital financeiro, trabalho e questão social. São Paulo: Cortez.

Telles, V. S. (2006). Direitos sociais. Afinal do que se trata? Belo Horizonte: UFMG. Marshall, T. H. (1967). Cidadania, classe social e status. Rio de Janeiro: Zahar.

Mota, A. E. (1995). Cultura da Crise e Seguridade Social: Um estudo sobre as tendências da previdência e da assistência social brasileira nos anos 80 e 90. São Paulo, Cortez.

O’Donnell, G. (2011). O regime democrático (ou a democracia política) e a cidadania como agência. In G. O’Donnell (Org.), Democracia, agência e estado. Teoria com intenção comparativa (pp. 20-40). São Paulo: Paz e Terra.

Paulo Netto, J. (1999). A construção do projeto ético-político do Serviço Social frente à crise contemporânea. In CFESS-ABEPSS. Capacitação em Serviço Social e política social: crise contemporânea, questão social e Serviço Social. Brasília: CEAD.

Política Nacional de Assistência Social (2005). PNAS/2004. Brasília.

Campello, T., \& Neri, M. C. (2013). Programa Bolsa Família: uma década de inclusão e cidadania. Brasília: Ipea.

Raichelis, R. (2000). Esfera pública e conselhos de assistência social: caminhos da construção democrática. São Paulo: Cortez.

Raichelis, R. (2000). Democratizar a Gestão das Políticas Sociais - Um Desafio a Ser Enfrentado pela Sociedade Civil. Serviço Social e Saúde: Formação e Trabalho Profissional. São Paulo: PUC.

Yazbek, M. C. (1995). A Política Social brasileira nos anos 90: a refilantropização da Questão Social. Cadernos Abong. Políticas de Assistência Social, 1(1), 15-24. 